\title{
The effect of antidepressant treatment on the HPA axis, changes in depression score and serum levels of TNF- $\alpha$ in depressed infertile women
}

\author{
Sedighen KeshavarZ ${ }^{1}$ \\ https://orcid.org/0000-0001-8603-1227 \\ BAHAR MORSHED-BEHBAHANI ${ }^{2}$ \\ Mohammad Ebrahim Parsanezhad 3 \\ https://orcid.org/0000-0002-0925-6374
}

AHMAD GHANIZADEH 4

Mehrap SAYADI ${ }^{5}$

https://orcid.org/0000-0003-2575-790X

Marzien AKBarZadeH ${ }^{6}$

https://orcid.org/0000-0002-4491-2437

Received: 02/03/2019 - Accepted: 09/28/2019

DOl: 10.1590/0101-60830000000222

1 Department of Midwifery, School of Nursing and Midwifery, Bushehr Province University of Medical Sciences, Bushehr, Iran.

2 Community Based Psychiatric Care Research Center, Department of Midwifery, School of Nursing and Midwifery, Shiraz University of Medical Sciences, Shiraz, Iran.

${ }^{3}$ Department of Gynecology and Obstetrics, Medical School, Shiraz University of Medical Sciences, Shiraz, Iran.

4 Department of Psychiatry, Research Center for Psychiatry and Behavioral Sciences, Hafez Hospital, Shiraz University of Medical Sciences, Shiraz, Iran.

${ }_{5}^{5}$ Department of Biostatistics, Cardiovascular Research Center, Shiraz University of Medical Sciences, Shiraz, Iran.

${ }_{6}^{6}$ Maternal-Fetal Medicine Research Center, Department of Midwifery, School of Nursing and Midwifery, Shiraz University of Medical Sciences, Shiraz, Iran.

\begin{abstract}
Objectives: This study aimed to explore the effect of antidepressant treatment on the HPA axis, changes in depression score, and serum levels of TNF- $\alpha$ in depressed infertile women. Methods: In this randomized controlled trial research, 60 infertile women who had undergone in vitro fertilization (IVF) treatment with depression scores between 16-47 were divided into two groups. The intervention group with fluoxetine capsule was under treatment for two months before the embryo transfer, while the control group was given placebo. Depression score, serum levels of tumor necrosis factor alpha (TNF- $\alpha$ ) as well as cortisol hormone levels were measured and recorded both before and after the intervention. The data were analyzed using SPSS version 21 software. Results: We analyzed the data related to 55 subjects who had undergone embryo transfer. 7 subjects in the intervention group and 3 in the control group got pregnant. We observed a significant decrease in the depression score $(p<0 / 001)$ and serum levels of cortisol $(p=0 / 001)$ in the intervention group. There was a significant increase in the serum levels of TNF- $\alpha$ in the intervention group $(\mathrm{p}<0 / 001)$. There was a significant difference between the two groups in the number of pregnancies $(\mathrm{p}=$ 0.04). However, there was no statistical difference between them with regard to the number of harvested oocytes $(p=0.174)$. Discussion: Decrease in depression score and cortisol level, and an increase in the levels of TNF- $\alpha$ in the intervention group caused any changes in the number of oocytes in comparison with the control group. However, the number of pregnancies was larger in the intervention group.
\end{abstract}

Keshavarz S et al. / Arch Clin Psychiatry. 2020;47(1):7-12

Keywords: TNF- $\alpha$, infertility, depression, HPA axis, treatment.

\section{Introduction}

Cytokines are small proteins that are released through white blood cells, especially macrophages or some tissues in response to stimulants ${ }^{1}$. Some cytokines such as interferon and tumor necrosis factor alpha (TNF- $\alpha$ ) are of cytotoxic effects, while some of them like growth factors have no cytotoxic effect. Some others have a prominent role in reproduction, gonadal function, implantation, and miscarriage ${ }^{2}$. TNF- $\alpha$ factor is one of the cytokines that has certain anti-inflammatory effects and is evaluated as a necessary index in many inflammatory diseases to assess the patients' responses to treatment. There is a relationship between an increase in the production of this cytokine and a variety of diseases like rheumatoid arthritis, atherosclerosis, diabetes, obesity, etc. ${ }^{3}$. Depression is thought of as another disorder that causes an increase in TNF- $\alpha$ and the number of cytokines in a person. On the one hand, depression leads to the production of inflammatory cytokines by activating the immune system. However, the patient's immunes system is influenced by simultaneous activation of HPA axis ${ }^{4}$. An increase in the level of inflammatory cytokines in depressed people will cause disorders in the brain function which will ultimately lead to activation of the hypothalamus-pituitary-adrenal axis (HPA) ${ }^{5-7}$. Cortisol is released as a result of activation of this axis and this biomarker affects pregnancy establishment and egg quality just as TNF- $\alpha$ does $^{8-11}$. It is because cortisol has a series of safety properties that can affect immunological conditions for implantation. In a study carried out in 2011 on 264 depressed infertile women undergoing IVF treatment, cortisol and norepinephrine hormones were measured in women's serum and follicular fluid. Higher pregnancy rates were reported in women with lower cortisol and norepinephrine levels ${ }^{12}$. According to Arslan's study, on the effect of TNF- $\alpha$ on pregnancy, TNF- $\alpha$ was significantly high in $60 \%$ (12 out of 20) of the women who had suffered from recurrent miscarriages; this shows the effect of this cytokine on the egg quality and lack of suitable implantation for the embryo'.

For many reasons, infertility has created a stressful situation with a lot of pain and suffering which leads to depression. It has been reported that prevalence of depression symptoms among infertile women is twice as much as that in fertile women ${ }^{13}$. Prevalence of 
depression and anxiety is high in women undergoing infertility treatment. 11 percent of these women suffer from major depression and 15 percent of them suffer from anxiety disorders ${ }^{14}$. As mentioned before, depression will cause disorders in the immune system and will, therefore, affect the chances of pregnancy. Thus, treating depression could help this group of women. Today, selective serotonin reuptake inhibitors (SSRI) such as fluoxetine are known as the most commonly used antidepressants among women of childbearing age and even pregnant women. The reason why these drugs are highly used is their appropriate therapeutic effect and very few side effects ${ }^{15}$. However, the effect of SSRIs on fertility and the ability to get pregnant has not been clearly specified ${ }^{13}$. According to the above mentioned points, Fluoxetine was used for depression treatment in this study, so that we could analyze its effect on the serum level of TNF- $\alpha$, changes in the HPA axis and the level of depression in people and determine the potential effect of these 3 factors on the patients' pregnancy.

\section{Methods}

\section{Patients and intervention}

The present study was a randomized controlled trial research which investigated the effect of Fluoxetine anti-depressant in women suffering from depression as well as its effect on depression score, serum levels of TNF- $\alpha$ and its subsequent changes in the function of HPA axis and finally fertility rate after IVF. This study was done from March 2014 to February 2016 in the clinic of infertility treatment at Shiraz University of Medical Sciences and obtained the approval of the Ethics Committee of Shiraz University of Medical Sciences (cod: CT-P9370-7870). The patients having undergone IVF filled out Beck Depression Inventory (BDI) and those with depression scores between 16 and 47 were sampled and studied provided that they met the inclusion criteria. Then, they were examined by a psychiatrist who prescribed 20 milligrams of Fluoxetine every day for two months. All the patients had a complete physical examination, and were asked about their medical history; all the tests were analyzed, and demographic questionnaire was filled out by all of them. All the patients were informed of the methodology and the possible side effects and filled out a written consent. Inclusion criteria were as follows: 1 . undergoing the first IVF; 2 . not suffering from chronic diseases, esp. infectious diseases, endocrine diseases and cancer; 3 . not being under medical treatment and not having undergone mental health counseling; and 4. having no history of drug abuse.

Exclusion criteria of the study were as follows: 1. patient's lack of willingness to continue cooperation; 2 . suffering from the side effects of Fluoxetine; and 3. treatment cancellation. The number of samples was determined by a statistical consultant based on the expected reduction in the depression score after the intervention and also according to similar studies conducted by Hubertus Himmerich (2006) and Tuglu (2003)16,17. After calculating a 10 percent potential loss, in each group 30 women and altogether 60 infertile women suffering from depression were selected based on purpose-oriented approach. After sample size calculation, permuted block randomization was used to assign patients into two groups; A: treatment with Fluoxetine capsule, B: control group using placebo. We assigned the patients into two groups in a 1:1 ratio. Then, 15 blocks of 4 (example AABB...) were prepared, and the patients were consecutively assigned to the blocks until the sample size in each group was completed (Figure 1). Fluoxetine and placebo capsules were prescribed according to the specific code, so that the patient himself, the physician, the operating room personnel, and the IVF personnel ward did not know which group the patient belonged to. All patients began daily HMG injections on day 2 of the menstrual cycle and were referred again on day 6 for ultrasound and serum estradiol levels. HCG injection and subsequent oocyte retrieval were performed only in patients with more than 4 follicles over $17 \mathrm{~mm}$ in their ovaries. About 36 hours after hCG injection, oocyte retrieval was performed. At the same time, the sperm sample of the patient's husband was taken in the morning and processed in the laboratory and then fertilized with the egg in the designated culture medium. The embryos were then frozen for transfer to the next cycle by vitrification method. Ovarian stimulation, uterine preparation, and embryo transfer were performed

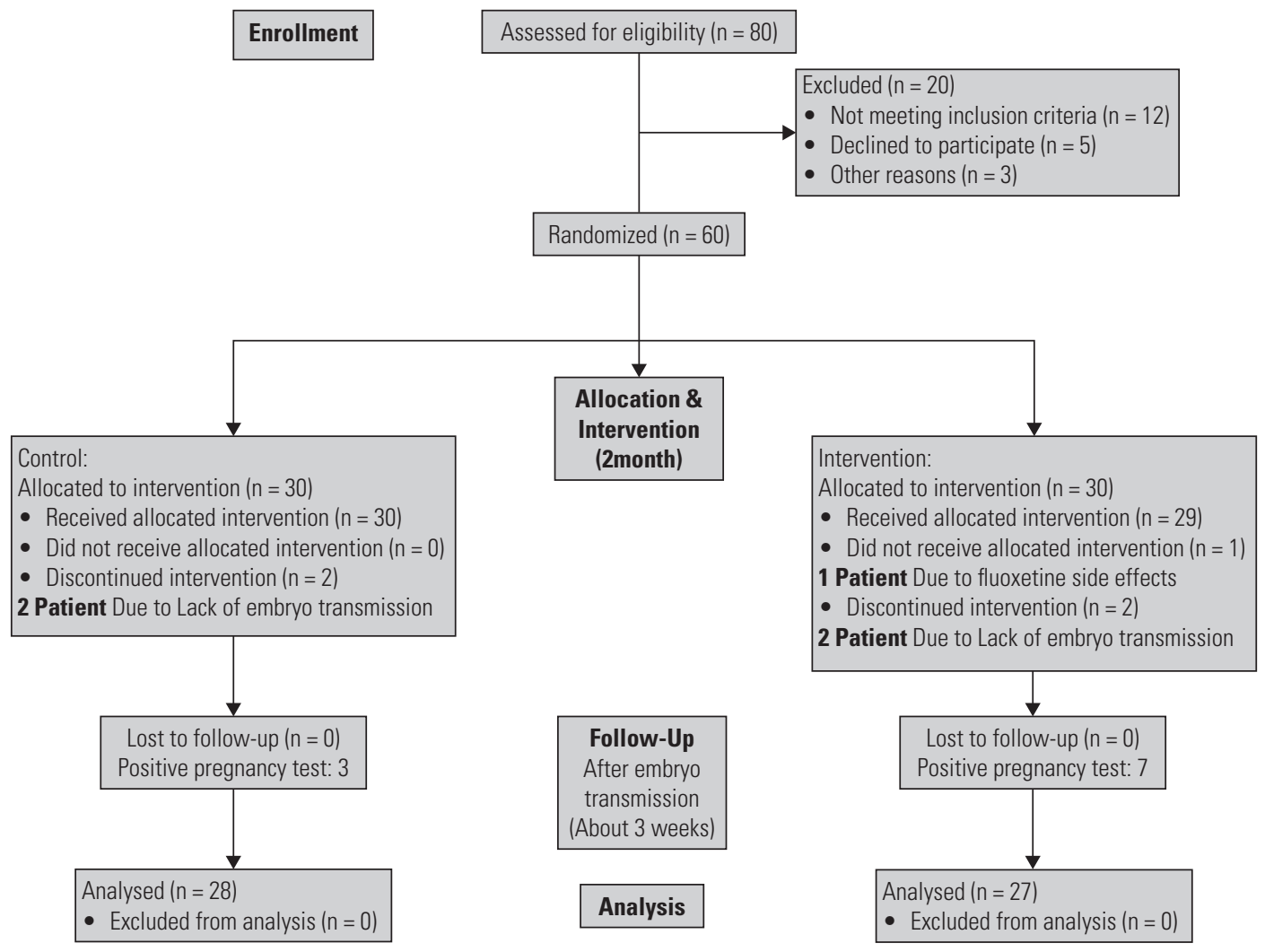

Figure 1. CONSORT flow diagram for sampling. 
for all patients in the same manner. 55 patients (28 in control group and 27 in intervention group) were able to freeze the embryo for the transfer day. The researchers checked the quality of all the embryos; in grade $\mathrm{A}$, the blastomeres were identical in size and there were no signs of fragmentation in them. In grade B, a number of the blastomeres were unequal in size and there were signs of fragmentation in $10 \%$ of them; Grades C and D were not transferred. Based on the embryo quality, the quality of all the transferable embryos were grades $\mathrm{A}$ or $\mathrm{B}$ and only one embryo was transferred.

The uterine preparation was done in the next cycle. The patient was taking $6 \mathrm{mg}$ daily of estradiol pills from the second day of menstruation (2 mg estradiol pills Aburaihan Pharmacy Co., Tehran, Iran-three pills a day), to prepare their endometrium for transfer; on the 9th, 10th, or 11th days after the beginning of menstruation, the thickness of the endometrium in each patient was measured using transvaginal sonography. If the thickness of the uterine wall was more than $8 \mathrm{~mm}$, the patient was administered an intramuscular injection of $100 \mathrm{mg}$ progesterone (50 mg progesterone ampules Aburaihan Pharmacy Co., Tehran, Iran -2 ampules were administered); 2 days after the progesterone injection, the embryo was transferred. Embryo transfer was carried out guided by ultrasound sonography; the catheter was entered into the cervix and the embryo was transferred (this method is called ultrasound-guidance or catheter guidance). BhCG test was done on the patients two or three weeks after the embryo transfer and if the result of the test was positive, biochemical pregnancy was confirmed.

\section{Data collection}

The data of every individual's depression score were recorded on the day of the surgery both before and after the intervention, using Beck Depression Inventory (BDI). Blood samples were taken for TNF- $\alpha$ serum check and cortisol simultaneously with filling out Beck questionnaire before and after the intervention. The first blood test was done in laboratory and the second one was done in the operating room before the embryo transfer between 8 and 9 a.m. Each time, $5 \mathrm{cc}$ of blood was taken. The samples were centrifuged immediately and kept at -70 degrees. The obtained values were then recorded, using ELISA method.

\section{Analyzed consequences}

1. Changes in TNF- $\alpha$ factor; 2 . Changes in the depression score; 3. Changes in the cortisol level; 4 . Positive pregnancy test (biochemical pregnancy rate) in the groups; and 5 . The number of harvested oocytes in each group. The serum levels of cortisol were measured by ELISA using a French BioMérieux kit in the serum, and used to measure TNF levels using the IBL ELISA kit (Human TNF-alpha), which was made in Ireland.

\section{Statistical analysis}

The data related to 55 patients under the study which had been obtained from demographic survey and clinical variables were recorded at the end of the treatment and IVF process in statistical analysis program and the following were done based on the objectives of statistical analysis study. T-test was used to analyze the difference between demographic data in the two groups; also, chi-square test was used to determine the difference between the two groups with regard to pregnancy, and paired t-test was used to determine the changes in variables before and after the intervention. SPSS software was used to analyze the data, and the significance level was considered to be 0.05 .

\section{Results}

There were 60 participants in this study. After considering the loss of some participants ( 3 in the medicine group and 2 in the control group), 55 subjects remained in the study, 28 in the control group and 27 in the Fluoxetine group. 10 out of 55 subjects who did embryo transfer got pregnant ( 7 in the intervention group and 3 in the control group). Two groups in terms of demographic characteristics, third day hormones, and cause of infertility were not statistically significant before intervention and the two groups were homogeneous (Table 1).

Positive pregnancy outcome in this study was considered to be a positive pregnancy test. According to the results of T-test, there was no significant difference between the two groups in terms of age, BMI, duration of marriage, and duration of infertility (Table 2). Paired sample test was used both before and after the intervention to

Table 1. Demographic characteristics and examination of day 3 hormones and causes of infertility

\begin{tabular}{|c|c|c|c|c|}
\hline & Fluoxetine $(n=27)$ & Control $(n=28)$ & \multirow[t]{2}{*}{$P$} \\
\hline & & Mean (SD) & Mean (SD) & \\
\hline \multicolumn{2}{|l|}{ Age (year) } & $30.47(4.54)$ & $30.43(5.34)$ & 0.516 \\
\hline \multicolumn{2}{|l|}{$\mathrm{BMI}\left(\mathrm{kg} / \mathrm{m}^{2}\right)$} & $25.06(3.53)$ & $26.61(5.34)$ & 0.262 \\
\hline \multicolumn{2}{|c|}{ Time of marriage (year) } & $8.08(5.23)$ & $8.26(5.88)$ & 0.916 \\
\hline \multicolumn{2}{|c|}{ Time of infertility (year) } & $5.60(4.84)$ & $5.82(4.06)$ & 0.870 \\
\hline \multicolumn{2}{|c|}{ FSH (third day) } & $6.07(3.17)$ & $6.31(2.33)$ & $0.555^{*}$ \\
\hline \multicolumn{2}{|l|}{ LH (third day) } & $4.77(2.67)$ & $4.69(3.94)$ & $0.340^{*}$ \\
\hline \multicolumn{2}{|l|}{ AMH (third day) } & $4.58(3.68)$ & 4.56 (3.68) & $0.919^{*}$ \\
\hline \multicolumn{2}{|l|}{ Est (third day) } & $61.83(21.07)$ & $56.49(37.67)$ & $0.223^{*}$ \\
\hline \multirow{5}{*}{ Cause of infertility } & & (Percent) & (Percent) & \\
\hline & Male & $39.1 \%$ & $34.8 \%$ & \multirow{4}{*}{$0.182^{* *}$} \\
\hline & Female & $21.7 \%$ & $47.8 \%$ & \\
\hline & Both & $17.4 \%$ & $13.0 \%$ & \\
\hline & Idiopathic & $21.7 \%$ & $4.3 \%$ & \\
\hline
\end{tabular}

* My Whitney Test. ${ }^{* *}$ Fisher exact test.

Table 2. Demographic characteristics of the two groups (fluoxetine and controls)

\begin{tabular}{|l|c|c|c|}
\hline \multirow{2}{*}{} & Fluoxetine $(\mathrm{n}=27)$ & Control $(\mathrm{n}=28)$ & \multirow{2}{*}{ P } \\
\cline { 2 - 4 } & Mean (SD) & Mean (SD) & 0.516 \\
\hline Age $($ year) & $30.47(4.54)$ & $30.43(5.34)$ & 0.262 \\
\hline BMl $\left(\mathrm{kg} / \mathrm{m}^{2}\right)$ & $25.06(3.53)$ & $26.61(5.34)$ & 0.916 \\
\hline Time of marriage (year) & $8.08(5.23)$ & $8.26(5.88)$ & 0.870 \\
\hline
\end{tabular}


analyze the changes in depression; as shown in Table 3, there was a significant decrease in the depression score in the intervention group.

As can be seen in the results of Paired t-test, there was a significant increase in the serum levels of TNF- $\alpha$ in the intervention group on the day of transfer. Paired t-test was also used to analyze the changes in cortisol both before and after the intervention. The results related to cortisol level in these two groups showed that there was a significant decrease in the cortisol serum level of the Fluoxetine group ( $\mathrm{p}=$ 0.001). However, these changes were not observed in the control group $(\mathrm{p}=0.734)$.

Seven participants in the Fluoxetine group and 3 in the control group got pregnant. According to the results of chi-square test, there was a significant statistical difference in the pregnancy rate between the control and intervention groups $(\mathrm{p}=0.04)$, and the number of pregnancies in the fluoxetine group was twice as many as those in the control group. The two groups were also compared in terms of the average number of harvested oocytes. According to the results of T-test, there was no significant statistical difference between the average number of oocytes in the control and intervention groups (Table 4).

\section{Discussion}

In this study, we analyzed the level of depression in the two groups after taking fluoxetine (intervention group) and placebo (control group) for two months and noticed that there was a significant decrease in the depression score measured using Beck inventory in the intervention group. This result could lend credence to the good effect of SSRI on decreasing the level of depression ${ }^{14}$. With an increase in the prevalence of depression among women of childbearing age and especially infertile women, these drugs have been widely used as they have helped to decrease the depression score to a considerable extent ${ }^{15}$. In the studies done by Faramarzi in the years 2008 and 2013, there was a significant decrease in the infertile patients' depression score as a result of the administration of Fluoxetine ${ }^{18,19}$.

In the present study, there was a significant increase in the levels of TNF- $\alpha$ after the intervention, possibly as a consequence of the significant decrease in serum cortisol levels in the intervention group, since cortisol inhibits TNF- $\alpha$ production. According to the Metaanalyses done by Dowlati and Liu in 2009 and 2011, depression affects the production of cytokines and increases the production of inflammatory factors, especially TNF- $\alpha$ and IL-620,21. Based on a study done by Shen et al. in 2010, the number of proinflammatory cytokines in the patients suffering from depression was significantly larger than those in non-depressed ones. However, after the patients were treated with antidepressants, there was a decrease in the level of these cytokines, but it was stiller larger than those in the nondepressed subjects ${ }^{4}$. According to Liu (2011), not only does the administration of Fluoxetine decrease the serum levels of TNF- $\alpha$, but also it decreases the level of its mRNA ${ }^{22}$. The difference between the results of this study and the other mentioned studies could be due to the fact that the level of inflammatory cytokines causes disorder in the brain function, as a result of which there will be changes in the function of HPA system ${ }^{21,23}$ and thus changes in the cortisol level. Accordingly, hypothalamus releases corticotropin releasing hormone $(\mathrm{CRH})$ and increases the release of adrenocorticotropin $(\mathrm{ACTH})$ from pituitary gland. As a result, cortisol is released from the adrenal gland ${ }^{16}$. An increase in the cortisol level leads to a decrease in TNF- $\alpha$ if there is negative feedback. Meanwhile, if there is a decrease in cortisol for any reason, there is an increase in TNF- $\alpha$ level once again ${ }^{24-26}$. As mentioned in the results of the study, there was a significant decrease in the cortisol level in the intervention group after the intervention, which was thought of as a stimulant for increasing TNF- $\alpha$ levels in people suffering from depression. In different studies, cortisol has been considered as the most important negative feedback signal for controlling cytokines and a suppressor of the production of cytokines ${ }^{27,28}$. A study done by Piletz in 2009 also indicated an increase in TNF- $\alpha$ after depression treatment ${ }^{29}$. In this study, venlafaxine and duloxetine were used and an increase in the TNF- $\alpha$ level in this study could be due to the intrinsic anti-flammatory effects of norepinephrine on the immune cells. Different results were reported in studies done by Eller on depressed people in 2008 and 2009. In these studies, people underwent various antidepressant treatments and there was only a decrease in the depression score, but no changes were observed in the TNF- $\alpha$ level ${ }^{30,31}$. Jazayeri (2010) studied the changes in HPA axis and cytokines after administration of fluoxetine on depressed people and analyzed the cortisol serum level, IL- 6 and IL-1 $\beta$. No changes were observed in the level of cytokines, but there was a significant decrease in the cortisol level after treatment ${ }^{32}$. In a study done by Pan et al., in which Icariin was used as an antidepressant, the TNF- $\alpha$ level showed a negative growth in some doses of the drug (75 mg) that had caused a decrease in the cortisol serum levels. On the other hand, no changes were observed in the TNF- $\alpha$ levels or cortisol level in lower doses of the drug $(35 \mathrm{mg})$. Accordingly, if antidepressants lead to effective successful treatment and a decrease in the cortisol level, there will be an increase in TNF- $\alpha^{33}$.

Table 3. Depression score, serum levels of TNF- $\alpha$ and cortisol level changes in both groups before and after intervention

\begin{tabular}{|l|c|c|c|}
\hline & $\begin{array}{c}\text { Depression } \\
\text { Mean }(S D)\end{array}$ & $\begin{array}{c}\text { Depression } \\
\text { Mean }(S D)\end{array}$ \\
\hline Fluoxetine $(n=27)$ & $24.95(7.98)$ & $18.52(9.63)$ & $p<0.001$ \\
\hline Control $(n=28)$ & $22.16(8.69)$ & $19.70(7.52)$ & 0.274 \\
\hline & TNF- $\alpha_{1}$ & TNF- $\alpha_{2}$ \\
Mean $(S D)$ & Mean (SD) & $p<0.001$ \\
\hline Fluoxetine $(n=27)$ & $71.98(6.22)$ & $360.17(47.86)$ & 0.106 \\
\hline & $85.32(7.28)$ & $109.49(32.58)$ & Cortisol \\
\hline Control $(n=28)$ & Cortisol & Mean (SD) & 0.001 \\
\hline Cluoxetine $(n=27)$ & Mean (SD) & $16.17(6.32)$ & 0.734 \\
\hline
\end{tabular}

Depression 1 , TNF- $\alpha_{1}$, Cortisol 1 : before intervention.

Depression $_{2}$, TNF- $\alpha_{2}$, Cortisol 2 : after intervention on the day of embryo transfer to the uterus.

Table 4. Difference between oocytes taken and pregnancy rate in two groups

\begin{tabular}{|l|c|c|c|c|c|}
\hline & Pregnant, $\mathrm{N}(\%)$ & Not pregnant, $\mathrm{N}(\%)$ & $\mathrm{P}$ & $\begin{array}{c}\text { Number of } \\
\text { Oocyte } \\
\text { Mean }(\mathrm{SD})\end{array}$ & $\begin{array}{c}\mathrm{P} \\
16.04(7.97)\end{array}$ \\
\hline Fluoxetine $(\mathrm{n}=27)$ & $7(25.92)$ & $20(74.07)$ & 0.04 & $13.0(6.36)$ & 0.160 \\
\hline Control $(\mathrm{n}=28)$ & $3(10.71)$ & $25(92.59)$ & & \\
\hline
\end{tabular}


There are 3 hypotheses on the effect of TNF- $\alpha$ on oocytes: 1. TNF- $\alpha$ affects the oocyte during its maturation and causes disorders in cleavage stage; 2 . TNF- $\alpha$ on the embryo after fertilization prevents it from growing and turning into blastocyst; and 3. TNF- $\alpha$ increases chances of apoptosis in blastomeres ${ }^{34}$. According to these hypotheses, TNF- $\alpha$ may not affect the number of oocytes and embryo implantation, but it increases the chances of early destruction of the embryo and miscarriage. According to a study done by Soto (2003) on the effect of TNF- $\alpha$ on fertility in cattle, TNF- $\alpha$ caused an increase in apoptosis and destruction of the embryo at the beginning of pregnancy although it had no effect on the oocyte maturation and fertilization ${ }^{34}$. In the present study, there was no significant difference in the two groups as to the number of oocytes, and an increase in TNF- $\alpha$ did not affect the number of oocytes either. According to a study done by Brogin Moreli (2012), the effect of TNF- $\alpha$ is shown through its impact on cell proliferation, differentiation and apoptosis in the tissue and disorders in these would lead to early loss of the fetus ${ }^{35}$. In other words, if faced with TNF- $\alpha$, there may be no difference in the number of oocytes and positive pregnancy test among the people. However, the embryo does have the ability to replicate and grow well after pregnancy, which could lead to early loss of pregnancy. In the present study, the two groups were also compared in terms of pregnancy. Accordingly, the number of pregnancies in the Fluoxetine group was twice as many as that in the control group and also an increase in TNF- $\alpha$ did not affect the pregnancy rate. Unlike our results, the findings of the studies done by Xu et al. (2018) and Boudjenah et al. (2014) showed that an increase in the TNF- $\alpha$ serum levels caused disorders in the embryo implantation, as a result of which there was a decrease in pregnancy rate during IVF ${ }^{36,37}$. According to Lee et al., an increase in the TNF- $\alpha$ level decreases the quality, but not the number of oocytes and there is no relationship between its level and pregnancy.

On the other hand, it could be concluded that a decrease in cortisol increased the pregnancy rate because the results of the studies done on this field have shown that cortisol changes the immunological conditions of the uterus and prevents the embryo implantation 12,38 . According to a study done by An et al. (2013), low levels of this hormone on the egg harvesting day increased the chances of the patients' pregnancy ${ }^{38}$. However, according to a study done by Csemiczky et al. (2000), there was no difference between pregnant and non-pregnant women in the cortisol level ${ }^{39}$.

\section{Conclusion}

The findings of the study showed that there was a significant decrease in the depression score of the intervention group as a result of taking fluoxetine. There was also a decrease in the cortisol serum levels that caused an increase in TNF- $\alpha$ due to the effect of negative feedback. However, an increase in the serum level of this cytokine did not have a negative effect on the number of oocytes and patients' pregnancy. The reason behind it could be the effect of this cytokine on the embryo opoptosis and an increase in the chances of miscarriage, not a decrease in pregnancy. On the other hand, a decrease in cortisol in the fluoxetine group provided the immunological conditions of the uterus for pregnancy and there was a significant increase in the number of pregnancies in the intervention group. There was no difference between the groups in terms of the number of harvested oocytes. We recommend that there should be an increase in the number of samples in future studies so that we can analyze the results more precisely and reach more certain conclusions.

\section{Strengths and limitations}

The most important limitation of this study was the small of number of depressed infertile patients that were willing to participate. Because of cultural, mental and family conditions, this group does not usually tend to take medicines, except for those related to IVF cycles, which led to a lot of limitations on our study. We recommend hperforming more precise and certain analysies through more sampling of these specific cases. Moreover, because of the TNF- $\alpha$ 's effects on increasing the rate of miscarriage, we suggest increasing the follow-up procedures in these patients to also evaluate this rate in future studies.

The strength of this study lies in the simultaneous analysis of the changes in the HPA axis through cortisol, changes in TNF- $\alpha$ cytokine after the intervention, and treating patients and continuing the follow-ups until they get fertile. However, the above-mentioned points have rarely been analyzed simultaneously in other studies.

\section{Acknowledgements}

The study is a part of the thesis by Sedigheh Keshavarz, that obtained the approval of the ethics committee of Shiraz University of Medical Sciences (cod: CT-P9370-7870) with the code of IRCT2014031116911n2.

The authors would like to thank Shiraz University of Medical Sciences, Shiraz, Iran, Mother and Child Infertility Center, and also Center for Development of Clinical Research of Nemazee Hospital and Dr Nasrin Shokrpour for editing the manuscript.

\section{References}

1. Wilczynski JR. Cancer and pregnancy share similar mechanisms of immunological escape. Chemotherapy. 2006;52(3):107-10.

2. Naz RK, Butler A, Witt BR, Barad D, Menge AC. Levels of interferon- $\gamma$ and tumor necrosis factor- $\alpha$ in sera and cervical mucus of fertile and infertile women: implication in infertility. J Reprod Immunol. 1995;29(2):105-17.

3. Parameswaran N, Patial S. Tumor necrosis factor- $a$ signaling in macrophages. Crit Rev Eukaryot Gene Expr. 2010;20(2):87-103.

4. Shen Y, Lu P, Wei L, Hu X, Chen W. Fluoxetine treatment for major depression decreases the plasma levels of cytokines. Afr J Biotechnol. 2010;9(43):7346-51.

5. Bierhaus A, Wolf J, Andrassy M, Rohleder N, Humpert PM, Petrov D, et al. A mechanism converting psychosocial stress into mononuclear cell activation. Proc Nat Acad Sci. 2003;100(4):1920-5.

6. Pavlov VA, Tracey KJ. The cholinergic anti-inflammatory pathway. Brain Behav Immun. 2005;19(6):493-9.

7. Shaked I, Meerson A, Wolf Y, Avni R, Greenberg D, Gilboa-Geffen A, et al. MicroRNA-132 potentiates cholinergic anti-inflammatory signaling by targeting acetylcholinesterase. Immunity. 2009;31(6):965-73.

8. Lee KS, Joo BS, Na YJ, Yoon MS, Choi OH, Kim WW. Relationships between concentrations of tumor necrosis factor-alpha and nitric oxide in follicular fluid and oocyte quality. J Assist Reprod Genet. 2000;17(4):222-8.

9. Arslan E, Çolakoğlu M, Çelik Ç, Gezginç K, Acar A, Çapar M, et al. Serum TNF- $a$, IL-6, lupus anticoagulant and anticardiolipin antibody in women with and without a past history of recurrent miscarriage. Arch Gynecol Obstet. 2004;270(4):227-9.

10. Hashemi S, Simbar M, Ramezani-Tehrani F, Shams J, Majd HA. Anxiety and success of in vitro fertilization. Eur J Obstet Gynecol Reprod Biol. 2012;164(1):60-4.

11. Li W, Newell-Price J, Jones G, Ledger W, Li T. Relationship between psychological stress and recurrent miscarriage. Reprod Biomed Online. 2012;25(2):180-9.

12. An Y, Wang Z, Ji H, Zhang Y, Wu K. Pituitary-adrenal and sympathetic nervous system responses to psychiatric disorders in women undergoing in vitro fertilization treatment. Fertil Steril. 2011;96(2):404-8.

13. Akioyamen LE, Minhas H, Holloway AC, Taylor VH, Akioyamen NO, Sherifali D. Effects of depression pharmacotherapy in fertility treatment on conception, birth, and neonatal health: a systematic review. J Psychosom Res. 2016;84:69-80.

14. Cesta CE, Viktorin A, Olsson H, Johansson V, Sjölander A, Bergh C, et al. Depression, anxiety, and antidepressant treatment in women: association with in vitro fertilization outcome. Fertil Steril. 2016;105(6):1594-602. e3.

15. Kaihola H, Yaldir FG, Hreinsson J, Hörnaeus K, Bergquist J, Olivier JD, et al. Effects of fluoxetine on human embryo development. Front Cell Neurosci. 2016;10:160.

16. Himmerich H, Binder EB, Künzel HE, Schuld A, Lucae S, Uhr M, et al. Successful antidepressant therapy restores the disturbed interplay between TNF- $\alpha$ system and HPA axis. Biol Psychiatry. 2006;60(8):882-8. 
17. Tuglu C, Kara SH, Caliyurt O, Vardar E, Abay E. Increased serum tumor necrosis factor-alpha levels and treatment response in major depressive disorder. Psychopharmacology. 2003;170(4):429-33.

18. Faramarzi M, Pasha H, Esmailzadeh S, Kheirkhah F, Heidary S, Afshar $Z$. The effect of the cognitive behavioral therapy and pharmacotherapy on infertility stress: a randomized controlled trial. Int J Fertile Steril. 2013;7(3):199-206.

19. Faramarzi M, Alipor A, Esmaelzadeh S, Kheirkhah F, Poladi K, Pash H. Treatment of depression and anxiety in infertile women: cognitive behavioral therapy versus fluoxetine. J Affect Disord. 2008;108(1-2):159-64.

20. Dowlati Y, Herrmann N, Swardfager W, Liu H, Sham L, Reim EK, et al. A meta-analysis of cytokines in major depression. Biol Psychiatry. 2010;67(5):446-57.

21. Liu Y, Ho RC-M, Mak A. Interleukin (IL)-6, tumour necrosis factor alpha (TNF- $\alpha$ ) and soluble interleukin-2 receptors (sIL-2R) are elevated in patients with major depressive disorder: a meta-analysis and meta-regression. J Affect Disord. 2012;139(3):230-9.

22. Liu D, Wang Z, Liu S, Wang F, Zhao S, Hao A. Anti-inflammatory effects of fluoxetine in lipopolysaccharide (LPS)-stimulated microglial cells. Neuropharmacology. 2011;61(4):592-9.

23. Hannestad J, DellaGioia N, Bloch M. The effect of antidepressant medication treatment on serum levels of inflammatory cytokines: a meta-analysis. Neuropsychopharmacology. 2011;36(12):2452-9.

24. Kapcala LP, Chautard T, Eskay RL. The protective role of the hypothalamic-pituitary-adrenal axis against lethality produced by immune, infectious, and inflammatory stress. Ann N Y Acad Sci. 1995;771(1):41937.

25. Tilders FJ, DeRuk RH, Van Dam AM, Vincent VA, Schotanus K, Persoons $\mathrm{JH}$. Activation of the hypothalamus-pituitary-adrenal axis by bacterial endotoxins: routes and intermediate signals. Psychoneuroendocrinology. 1994;19(2):209-32.

26. Silverman MN, Pearce BD, Biron CA, Miller AH. Immune modulation of the hypothalamic-pituitary-adrenal (HPA) axis during viral infection. Viral Immunol. 2005;18(1):41-78.

27. Arzt E, Kovalovsky D, Igaz LM, Costas M, Plazas P, Refojo D, et al. Functional cross-talk among cytokines, T-cell receptor, and glucocorticoid receptor transcriptional activity and action. Ann N Y Acad Sci. 2000;917(1):672-7.
28. Besedovsky H, Del Rey A. The cytokine-HPA axis feed-back circuit. Z Rheumatol. 2000;59 Suppl 2:II/26-30.

29. Piletz JE, Halaris A, Iqbal O, Hoppensteadt D, Fareed J, Zhu H, et al. Pro-inflammatory biomakers in depression: treatment with venlafaxine. World J Biol Psychiatry. 2009;10(4):313-23.

30. Eller T, Vasar V, Shlik J, Maron E. Pro-inflammatory cytokines and treatment response to escitalopram in major depressive disorder. Prog Neuropsychopharmacol Biol Psychiatry. 2008;32(2):445-50.

31. Eller T, Vasar V, Shlik J, Maron E. Effects of bupropion augmentation on pro-inflammatory cytokines in escitalopram-resistant patients with major depressive disorder. J Psychopharmacol. 2009;23(7):854-8.

32. Jazayeri S, Keshavarz SA, Tehrani-Doost M, Djalali M, Hosseini M, Amini $\mathrm{H}$, et al. Effects of eicosapentaenoic acid and fluoxetine on plasma cortisol, serum interleukin-1beta and interleukin-6 concentrations in patients with major depressive disorder. Psychiatry Res. 2010;178(1):112-5.

33. Pan Y, Zhang WY, Xia X, Kong LD. Effects of icariin on hypothalamic-pituitary-adrenal axis action and cytokine levels in stressed Sprague-Dawley rats. Biol Pharm Bull. 2006;29(12):2399-403.

34. Soto P, Natzke R, Hansen P. Actions of tumor necrosis factor-alpha on oocyte maturation and embryonic development in cattle. Am J Reprod Immunol. 2003;50(5):380-8.

35. Brogin Moreli J, Cirino Ruocco AM, Vernini JM, Rudge MVC, Calderon IMP. Interleukin 10 and tumor necrosis factor-alpha in pregnancy: aspects of interest in clinical obstetrics. ISRN Obstet Gynecol. 2012;2012.

36. Xu B, Zhou M, Wang J, Zhang D, Guo F, Si C, et al. Increased AIF-1-mediated TNF- $\alpha$ expression during implantation phase in IVF cycles with GnRH antagonist protocol. Hum Reprod. 2018;33(7):1270-80.

37. Boudjenah R, Molina-Gomes D, Torre A, Boitrelle F, Taieb S, Dos Santos E, et al. Associations between Individual and combined polymorphisms of the TNF and VEGF genes and the embryo implantation rate in patients undergoing in vitro fertilization (IVF) programs. PloS One. 2014;9(9):e108287.

38. An Y, Sun Z, Li L, Zhang Y, Ji H. Relationship between psychological stress and reproductive outcome in women undergoing in vitro fertilization treatment: psychological and neurohormonal assessment. J Assist Reprod Genet. 2013;30(1):35-41.

39. Csemiczky G, Landgren BM, Collins A. The influence of stress and state anxiety on the outcome of IVF-treatment: Psychological and endocrinological assessment of Swedish women entering IVF-treatment. Acta Obstet Gynecol Scand. 2000;79(2):113-8. 